\title{
伊乐藻等几种沉水植物的生物量 和生产量测定以及竟争态势试验
}

\author{
胡 耀 辉 \\ (中国科学完南京地理与湖泊研究所,柬京 210008)
}

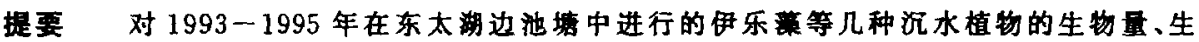

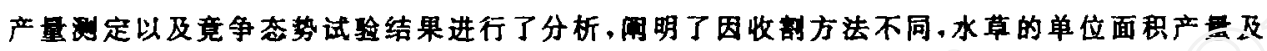

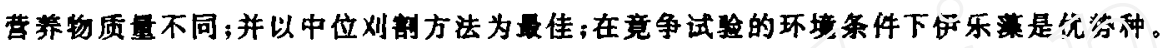

关整词沉水植物生产量 竟争

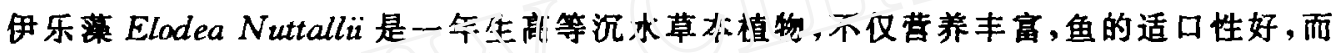
且生长迅速, 产量高、在东太湖区，值点都自长到水面, 越到上部分枝越多, 植丛的生物量分

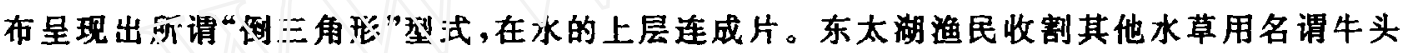
刀,刀口与论证保持一定距离, 被割的植物尚有再生能力。而收割伊乐萧是用两根竹等插人 伊乐落植丛中, 两手同时转动两根竹等, 伊乐藻则连株带根绕缠在两根竹等上, 我们称它为 “绞收”。这种绞收方法, 虽然一个人就可以作业, 劳动强度小, 收获量大, 但当年的再生能力 扱小，甚至影响第二年植被的炇复。就是说每年的生产量最多相当于生物量。

杨清心等 ${ }^{[2]}$ 在东太湖进行伊乐萧引种试验时已经注意到,在人工栽培条件下一年四季 都能正常生长, 但在自然条件下, 东太湖伊乐落表现出以年为周期的生长节律,夏季高温时 生长停滞, 进入休眠状态, 至秋季再度生长, 形成新的群落。可见, 只要在人工管理的条件下, 合理收割, 伊乐藻的生产潜力是很大的。

伊乐落盛长期的季节早于其他水草,最大生物量往往出现在 6 月中、下旬。但东太湖渔

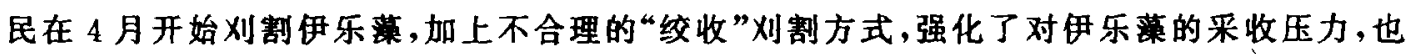
阻抑了伊乐藻分布区的进一步扩大,制约了伊乐藻生产能力的进一步提高。

湖泊围栏养鱼面积不断扩大, 草食性鱼类的产量不断提高, 以东太湖为例, 除了湖区大 量围栏养鱼需要措取大量水草，湖周围大量内塘养鱼每天有众多船只人湖打捞水草, 据统 计,仅经萃白港闸口进入湖区捞水草的船只达 80 只/天以上。湖中水草面临着求大于供的压 力。因此,除了引入国外生长繁育能力强、营养丰富的水生高等植物外, 如何掌握植物的生长 规律, 采取合理的采割方法和采割时间, 也是提高湖泊水生高等植物产量的必要手即。“伊乐 藻一草鱼圈养人工复合生态系统建设”课题, 其中就有以伊乐落种植为中心, 提高伊乐藻产 量的研究任务。为此, 我们以伊乐菒为主,再包括东太湖的优良沉水植物一一黑菜 Mydrilla verticillate 和微齿眼子菜 Pltamoyeton maackianus, 通过不同的刈割方法比较, 了解它们的生 物量和生产量。还同时进行了伊乐莱与其他几种沉水植物的竟争态势试验。 
由于该研究在湖中很难操作和做到定量化,所以试验安排在湖边的两个池塘和两个水 泥池内进行。每一种植物试验期间至少一周年。

\section{1 材料与方法}

\section{1 四种沉水植物的主要生物学特点}

伊乐藻: 崔雄异株, 属一年生沉水草本植物。植株鲜绿柔嫩,菱节上的叶腋内可分生新 枝,有时还伴有细线状不定根; 叶无柄,三枚轮生,枝株呈倒圆锥形分布。适应性强, 人工栽植 易成活。1986 年引入的是雄性植株,所以东太湖的都是营养繁殖的群体。主要分布在近岸水

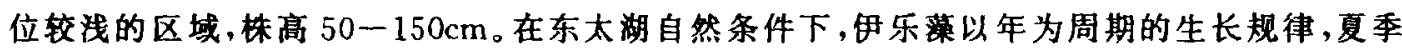
高温生长停滞,进人休眠状态,秋季再度生长,形成新的种群。本试验完全用植株剪断后较植 形成伊乐藻种群。

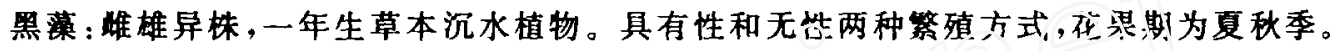

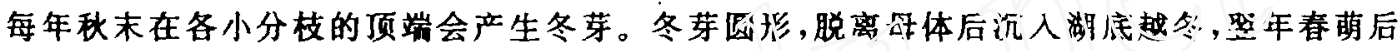

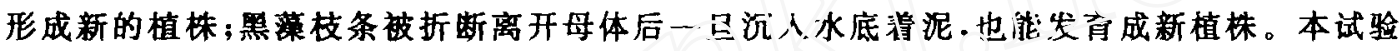
完全用植株剪断后载植形成黑藻种㪊。

微齿眼子莱:多售经华本沉水植物、禁系多达，植株丛生、喜温暖，到冬季整个植株枯黄，

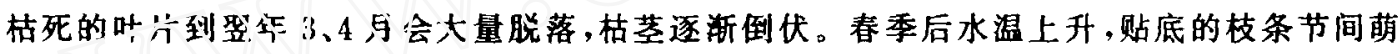

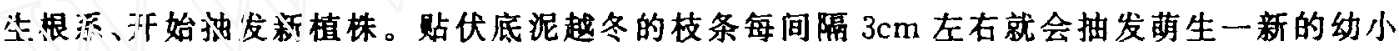
植措，每根贴泥枝条一般可抽发出 5 至 8 枝新植株。因此,微齿眼子莱的种群结构中,有多年 的老植株,也有当年新生的植。微齿眼子菜的开花结果期一般在 6-9 月,8一-9月为结果 盛期,9-10月间,其生物量达到最大值,12月开始停滞生长。微齿眼子菜也可无性繁殖。本 试验用移载方式形成种群。

金鱼藻: 倠雄同株,具有性和无性两种繁殖方式; 9-10月其成熟的果实脱离母体后沉 入水底越冬,待翌年春季萌发新的植株。本试验用移栽方式形成种群。

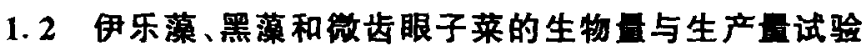

在东太湖边选定一池塘, 长 $56 \mathrm{~m}$, 宽 $17 \mathrm{~m}$, 深 $1.5 \mathrm{~m}$, 按需要调控水深。用较密的胶丝窗纱 网将该塘分隔成 3 个区，每个区再用塑料薄膜分隔成面积相等的 16 个小格,伊乐藻区每小 格面积为 $8.96 \mathrm{~m}^{2}$, 轮叶黑落区和微齿眼子莱区中的每个小格面积均为 $4.48 \mathrm{~m}^{2}$ (图 1)。谟料 薄膜高 $30 \mathrm{~cm}$, 插人泥面下 $15 \mathrm{~cm}$, 以防止小格之间植物互相渗透影吻棈度。

\begin{tabular}{|c|c|c|c|c|c|c|c|c|c|c|}
\hline \multicolumn{4}{|c|}{ 伊乐溜 } & \multicolumn{2}{|c|}{ 微齿昨一染 } & \multicolumn{3}{|c|}{ 汭 草 } & \multicolumn{2}{|c|}{ 轮叶黑澡 } \\
\hline A & B & $\bar{C}$ & D & $A, B$ & CD & $\mathrm{A} B$ & & D] & A] $B$ & C $[\mathrm{D}$ \\
\hline B & C & D & $\mathrm{A}$ & B] C & D $\mathrm{A}$ & B $C$ & $D$ & A & B $\mathrm{C}$ & $D$ A \\
\hline $\bar{C}$ & D & A & $\bar{B}$ & C $D$ & $\bar{A}, \bar{B}$ & C] $D$ & & B & C] & A $B$ \\
\hline D & $A$ & $\mathrm{~B}$ & $\mathrm{C}$ & D] $A$ & $B, C$ & D $A$ & $B$ & C. & $D A$ & $B, C$ \\
\hline
\end{tabular}

图 1 三种水草生物量与生产量试验设置

Fig. 1 Topological design of experiment of biomass and annual production of 3 submerged plants 
每种水草按 A、B、C、D 分四组, A 组采用中位刈割法收割, B 组采用底部(泥面以上 $5 \mathrm{~cm}$ 左右处)刚割法收割, C 组采用渔民惯用的用两根竹等“绞收”收割。D组为最大生物量即对 照组。为尽可能消除地块间的底泥肥力、光线、土培结构等因子影响, A、B、C、D四组都以拉 丁方布设。

1993 年 4 月 8 日,在试验池塘分别插植和移载伊乐藻、黑藻和微齿眼子菜。同一种水草

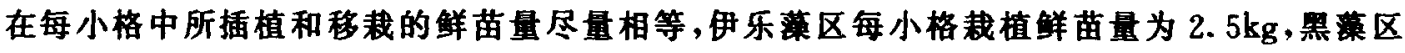
每小格我植鲜苗量为 $1.5 \mathrm{~kg}$, 微业眼子莱区每小格移栽苗量为 $2 \mathrm{~kg}$ 。等插植或移载的苗成活 后，检查每小格中是否均匀,如不均匀再用补载方法使其均匀后开始实验。

每种水草除 D 组对照组外, 其余 $A 、 B 、 C$ 各组均是当水草长达水面时进行收割,各组收 割次数取决于复长情况。

\section{3 伊乐薄、黑藻、微齿眼子莱和金鱼薄的竟争态势试验}

在东太湖边选定两个面积均为 $25.5 \mathrm{~m}^{2}$ 的水池，水池 深 $1 \mathrm{~m}$, 池中水通过水票从东太湖豆人,水深一般控制在 $90 \mathrm{~cm}$ 左右。

试金从1994年4月 21 日开始,采用临笑法和涅命 法两种方案同时进行。

（1）临界法：挍勘公所示布谓，A、B、C、D四个区分

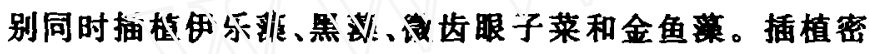
度尽可能一致。备区之间不设置任何分隔物，四种水草之 间边界用悬于水面上的拉绳作标记。

（2）混合法:即四种水草等量混合插植。先将选择好 的四种水草鲜苗切成 $20 \mathrm{~cm}$ 长, 然后称取各种水草 $2.5 \mathrm{~kg}$, 混合均匀, 插植于第二号水池中。

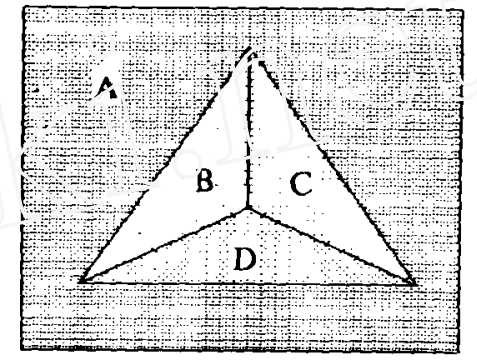

图 2 伊乐等几种沉水 植物竟争态势临界法设異 Fig. 2 Topological design of competitive growth experiment of the four submerged plants

2 结果与讨论

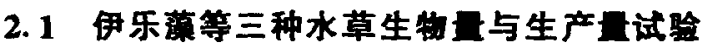

因收割方法不同，三种水草的单位面积产量差异较大,其中均是中位刈割法所获得的鲜 草量最多(表 1)。一年内获得的鲜草总量 (刈害后洗净并用洗衣机甩干筒转动 30 秒称量)分 别为: 伊乐落 $5.88 \mathrm{~kg} / \mathrm{m}^{2}$, 黑落 $4.48 \mathrm{~kg} / \mathrm{m}^{2}$, 微齿眼子菜 $4.7 \mathrm{~kg} / \mathrm{m}^{2}$ 。根据 Logistic 种群最大增 长原理,要维持种群的持续高速生长发育,其种群密度或生物量宜保持在 $50 \%$ 的容量。中位 刈割法保持了水草块速再生发育所需的生物量,使得一年中收割次数多,产量大。伊乐莫可

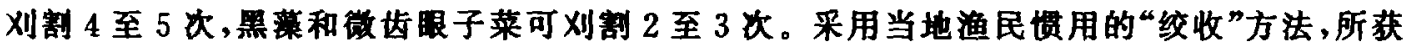
产量最少,还不及最大生物量。一年中伊乐萧仅为 $2.34 \mathrm{~kg} / \mathrm{m}^{2}$, 黑菜仅为 $2.23 \mathrm{~kg} / \mathrm{m}^{2}$, 呲齿眼 子菜仅为 $2.6 \mathrm{~kg} / \mathrm{m}^{2}$, 分别比最大生物量少 $47.8 \%, 64.6 \%$ 和 $19.2 \%$ 。同中位割法比较,三 种水草一年内单位面积生产量分别少 $151.3 \%$ 、100.9\%和 $80.7 \%$ 。“绞收”法之所以单位面 积产量如此低, 主要原因除了过度采收了植物再生所需的生物量外, 还在很大程度上损坏了 植物根系及新的生长点, 严重破坏了植物再生能力。绞收期越早, 破坏程度越大,产量也越 低。结果表明，只要改进水草的收割方法，在面积相同的条件下，每年可增加一倍的鲜草量。 
表 1 最大生物量及不同收制方法的产量

Tab. 1 Peak biomass and annual production by different means of harvest

\begin{tabular}{|c|c|c|c|c|c|c|c|c|c|}
\hline 种类 & \multicolumn{3}{|c|}{ 伊乐意 } & \multicolumn{3}{|c|}{ 黑意 } & \multicolumn{3}{|c|}{ 䫓齿眼子莱 } \\
\hline 收部方式 & 中位刘割 & 底部刘割 & 绞收 & 中位则訓 & 底部则到 & 绞收 & 中位刈富 & 底部刏菑 & 绞收 \\
\hline 年内收部次数 & 4 & 2 & 2 & 3 & 2 & 1 & 2 & 2 & 1 \\
\hline 年内鲜草产田 $\left(\mathrm{kg} / \mathrm{m}^{2}\right)$ & 5.88 & 3.75 & 2. 34 & 4.48 & 3.78 & 2. 23 & 4.7 & 3.87 & 2.6 \\
\hline 最大生物贯 $\left(\mathrm{kg} / \mathrm{m}^{2}\right)$ & \multicolumn{3}{|c|}{3.46} & \multicolumn{3}{|c|}{3.67} & \multicolumn{3}{|c|}{ 3. 1} \\
\hline
\end{tabular}

收割方式因收割植物体的部位不同,鲜草的营养成分含量也不同(表 2)。将三种收割方 法所获得的植物鲜草量及营养成分含量推算出蛋白质和脂肪的总量进行比较，也都是以中 位刈割法所获的量最多，其次是底部刈割法，“绞收”法最少(表 3)。

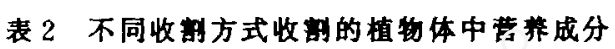

Tab. 2 Nutrients composition of plants in different means ot harvest

\begin{tabular}{|c|c|c|c|c|c|c|c|}
\hline \multirow{2}{*}{ 种 类 } & \multirow{2}{*}{ 收韵方式 } & \multirow{2}{*}{ 含水量(\%) } & \multicolumn{5}{|c|}{ 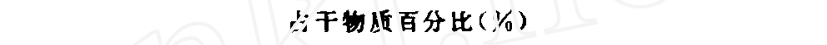 } \\
\hline & & & 粗蹎白合 & 蚟脂肪 & 屈平维 & 灰 分 & 无氛没出物 \\
\hline \multirow{3}{*}{ 薏 } & 中位刘部 & 89.2 & $23 j ?$ & 2.03 & 23.12 & 18.05 & 33.43 \\
\hline & 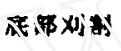 & E3. 28 & 20.15 & 2.88 & 26.63 & 17.86 & 32.48 \\
\hline & 收 & 82.86 & 19.96 & 2.46 & 26.71 & 17.66 & 33.21 \\
\hline \multirow{3}{*}{ 孉 } & 中位刈嘴 & 86.86 & 20.46 & 3.75 & 27.12 & 18.51 & 30.16 \\
\hline & 底部刈割 & 84.62 & 20.14 & 2.54 & 29.15 & 18.46 & 29.71 \\
\hline & 收 & 84.2 & 19. 36 & 2.61 & 29.63 & 19.46 & 28.94 \\
\hline \multirow{3}{*}{ 䵇些眼子莱 } & 中位刈韵 & 88.42 & 16.55 & 2.62 & 18.52 & 20.56 & 41.75 \\
\hline & 底部刈割 & 87.74 & 17.1 & 2. 71 & 20.16 & 21.09 & 38.94 \\
\hline & 绞收 & 84.25 & 17.27 & 2.73 & 21.62 & 21.83 & 36.55 \\
\hline
\end{tabular}

表 3 不同收割方法获得相当于蛋白质和脂眆量的比较

单位: $g /\left(a \cdot \mathrm{m}^{2}\right)$

Tab. 3 Annual output of protein and lipids of plants by different means of harvest

\begin{tabular}{|c|c|c|c|c|c|c|c|c|c|c|}
\hline 种 & & \multicolumn{3}{|c|}{ 用乐草 } & \multicolumn{3}{|c|}{ 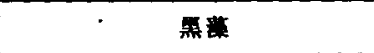 } & \multicolumn{3}{|c|}{ 散此眼子莱 } \\
\hline 收静力 & & 中位刈割 & 底部刘割 & 绞收 & 中位刘部 & 底部对害 & 绞收 & 中位犾副 & 底部对話 & 绞收 \\
\hline 蛋白 & 质 & 150 & 127 & 80 & 90 & 81 & 71 & 121 & 117 & 68 \\
\hline 脂 & 肪 & 13 & 18 & 10 & 14 & 13 & 11 & 22 & 15 & 9 \\
\hline
\end{tabular}

综上所述,无论是鲜草产量还是营养物质产量, 比较结果, 三种水草都以中位刚割法为 最佳,是值得推广的收割方法。

\section{2 伊乐蓓等四种沉水植物竟争态势}

\section{2 .1 临界法}

1994 年 6 月 10 日观激，伊乐萧和黑菒生长块,种群密度大, 植株高; 微柴眼子菜和金鱼

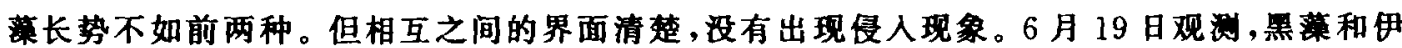


乐藻已长至水面,密度很大,在界面处都明显侵人到金鱼藻和微齿眼子菜的种群区域内。伊 乐藻和黑藻之间没有侵人现象。7月10日,伊乐藻和黑藻不仅在界面处侵人微齿眼子菜和 金鱼藻种群中深人达 $20-35 \mathrm{~cm}$, 而且在微齿眼子莱和金鱼藻的种群区域中部有伊乐藻和黑

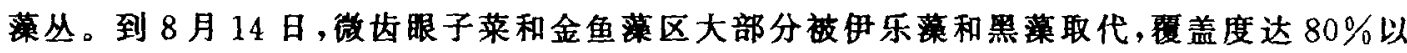
上。伊乐藻和黑㩰之间仍未出现互侵现象。9月15日,分别在微选眼子菜和金鱼藻原种群区 域中随机抽样一平方米,底部刘割后分离出各种水草鲜重分别为: 微齿眼子菜种群区计有微 齿眼子菜 $355 \mathrm{~g}$ 、伊乐藻 $1350 \mathrm{~g}$ 、黑㩰 $550 \mathrm{~g}$; 金鱼藻种群区计有金鱼藻 $510 \mathrm{~g}$, 伊乐藻 $1050 \mathrm{~g}$, 黑 藻 $595 \mathrm{~g}$ 。伊乐藻比黑藻侵入性强、侵人面大。

一年后的 1995 年,各种水草都经过了一次生长发育期和休眠期, 它们的竟争态势已成 格局。1995年 7 月 18 日,整个种植区乃至整个水池全部生长伊乐藻,其它三种水草基本不 存在。分别在四种水草的原种植区 $A 、 B 、 C 、 D$ 中(图 2) 拔收 $1.5 \mathrm{~m}^{2}$, 获得的鲜草全是乐㩰, 分别为 $8.45 \mathrm{~kg} 、 5.5 \mathrm{~kg} 、 5.75 \mathrm{~kg}$ 和 $5 \mathrm{~kg}$ 。

\section{2 .2 混合法}

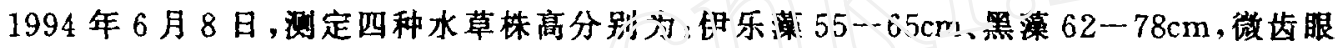

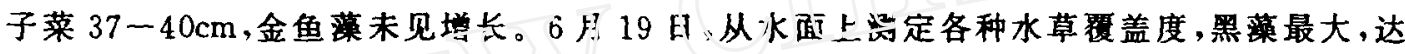

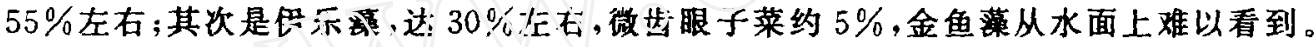

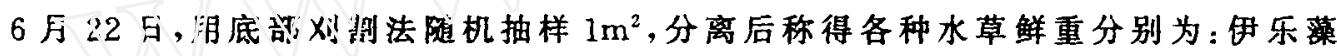
$320 \mathrm{~g}$ 、黑藻 $8 ! 5 \mathrm{~g}$ 、微齿眼子菜 $31 \mathrm{~g}$, 金鱼藻 $10 \mathrm{~g} 。 8$ 月 12 日,在末刈割处再随机取样 $1 \mathrm{~m}^{2}$,分离 称鲜重，伊乐落 $640 \mathrm{~g}$, 株高 68 厘米; 黑落 1050 克, 株高 78 厘米; 微齿眼子菜 150 克,株高 $41 \mathrm{~cm}$; 金鱼落 $35 \mathrm{~g}$ ，高 $28 \mathrm{~cm}$ 。在植物群落中，黑菠占一定优势。

至 9 月 15 日,在 6 月 22 日刈割的那一处植物已炇复,生物密度和植株高度与未收割处 的一样。再次从底部刏割,分离后称得鲜草重分别为: 伊乐藻 $845 \mathrm{~g}$, 株高 $70-75 \mathrm{~cm}$; 黑藻 $1005 \mathrm{~g}$, 株高 $70-75 \mathrm{~cm}$; 微齿眼子菜 $295 \mathrm{~g}$, 株高 $55-62 \mathrm{~cm}$; 金鱼菜 $150 \mathrm{~g}$, 株高 $40-45 \mathrm{~cm}$ 。显 然,经过刘割后，矤复能力伊乐藻和黑㩰强于微齿眼子莱和金鱼藻。

一年后的 1995 年, 试验池基本被伊乐藻覆盖,其它三种水草几乎不存在。1995年 7 月 18 日, 随机取样两处,各 $1 \mathrm{~m}^{2}$, 获鲜草全是伊乐藻, 分别为 $8.75 \mathrm{~kg}$ 和 $8.1 \mathrm{~kg}$ 。

两种试验结果表明, 4 种水草中数伊乐落竟争力最强。黑藻在其生长昍期,空间竟争能 力和伊乐藻比较, 难分强弱, 但经过冬季休眠期后,翌年复萌再生时, 其竟争力远不如伊乐 㩰。笔者认为主要原因有二：一是伊乐藻在适宜条件下，增长迅猛，6月至 8 月期间,伊乐藻 的日平均伸长达 $1.9 \mathrm{~cm}$, 最大伸长速度可达 $3-4 \mathrm{~cm} / \mathrm{d}^{[1]}$ 。如此块速地伸长使其植㧼于其 它水草长到上层水面,在光照充足的上层水面大量分枝,形成类似于乔木的倒三角形的生物 量垂直分布, 在光竞争方面处于明显优势，抑制了微齿眼子菜和金鱼藻正常的生长发育; 二 是伊乐藻较酎寒, 水温 $5 \mathrm{C}$ 即可生长,而轮叶黑藻、微齿眼子菜和金鱼藻等冬季休眠期较长, 早春它们还处于休眠期时, 伊乐藻已处于生长期。因而, 伊乐藻在冬春时空竞争方面占有优 势。

以上仅是提供了一个初步的竟争试结验果。在自然状态下,植物间的竟争要比人为设计 的复杂得多,这方面的试验还有待深人。 
3 小结

（1）收割方法不同会影响水草的年生产量。试验结果表明中位刈割是最佳收割方法, 比 绞收可多产鲜草 1.5 倍左右。

（2）临界法和混合法两种竟争试验结果都显示伊乐落在同黑㩰、微齿眼子莱及金鱼藻 的竟争中是优势种。

$$
\text { 考文获 }
$$

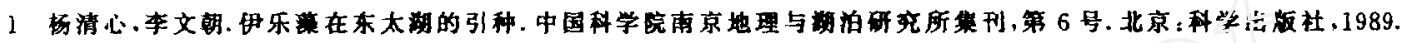
$84-91$

\title{
TESTING STID\% OF BIOIMASS, PRODUCTION AND COMPETITY' GROWTH OF ELODEA NUTTALLII AND OTHER SUBMERGED PLANTS
}

\author{
Hu Yaohui \\ (Nanjing Institute of Geography \& Limnology. Chinese Academy of Sciences, Nanjing 210008)
}

\begin{abstract}
Abstreat
The biomass, production and competitive growth of Elodea Nuttallii and other submerged plants was studied in a pond by Taihu Lake side during 1993-1995. The study shows that means of harvest affect the production of the submerged plants, cutting its half biomass per time make peak annual output, and Elodea Nuttallii is dominant species under the environmental condition of experiment.
\end{abstract}

Key Words Submerged plant, production, competition 